\title{
Altered mRNA expression of glycosyltransferases in human colorectal carcinomas and liver
} metastases

\author{
T Petretti, W Kemmner, B Schulze, P M Schlag
}

\begin{abstract}
BackgroundlAims-Biosynthesis of carbohydrate structures is tissue specific and developmentally regulated by glycosyltransferases such as fucosyltransferases, sialyltransferases, and $\mathrm{N}$-acetylglucosaminyltransferases. During carcinogenesis, aberrant glycosylation leads to the development of tumour subpopulations with different adhesion properties. Therefore alterations in glycosyltransferase mRNA expression in colorectal carcinomas were examined by semiquantitative reverse transcription-polymerase chain reaction (RT-PCR).
\end{abstract}

Methods-Colorectal carcinoma specimens were classified and characterised according to the WHO/UICC system. Expression of fucosyltransferases FT-I, FT-III, FT-IV, FT-V, FT-VI, and FT-VII, sialyltransferases ST3Gal-I, ST3Gal-III, ST3Gal-IV, and ST6Gal-I, $\beta 1,4-$ galactosyltransferase, and $\beta 1,6-N a c e t y l g l u c o-$ saminyltransferase $\quad \mathrm{V}$ (GNT-V) was screened simultaneously in extracts of 22 homogenised tumour specimens by RTPCR and compared with corresponding mucosa from each patient. Also 12 adenomas and 17 liver metastases of colorectal carcinomas were examined.

Results-GNT-V expression was enhanced in colorectal adenomas $(p=0.039)$, carcinomas $(p<0.001)$, and liver metastases of colorectal carcinomas $(\mathrm{p}<0.001)$. Also, expression of fucosyltransferase FT-IV was increased in colorectal adenomas $(p=$ $0.039)$ and carcinomas $(p<0.001)$. In addition, fucosyltransferase FT-I $(p<0.001)$ and sialyltransferases ST6Gal-I (p = $0.004)$ and ST3Gal-III ( $p=0.001)$ showed increased expression in carcinoma specimens. On the other hand, fucosyltransferase FT-III was less abundantly expressed in carcinomas exhibiting distant metastases $(p=0.046)$ and in highly invasive tumours $(p=0.041)$.

Conclusions-Glycosyltransferase mRNA expression is significantly altered in colorectal adenomas and carcinomas isolated from surgical specimens. RT-PCR determination of specific glycosyltransferases may be helpful for earlier detection of carcinomas and for tumour prognosis. (Gut 2000;46:359-366)

Keywords: colorectal carcinoma; adenomas; liver metastasis; glycosyltransferases; tumour prognosis; mRNA expression
Aberrant glycosylation of membrane components is of great relevance in cellular recognition processes and leads to the development of tumour cell subpopulations with different adhesion properties. ${ }^{12}$ Biosynthesis of carbohydrate structures is tissue specific and developmentally regulated by the activity of glycosyltransferases such as fucosyltransferases, sialyltransferases, and galactosyltransferases. ${ }^{34}$ For instance, the activity of human Gal $\beta 1,4$ GlcNAc $\alpha 2,6-$ sialyltransferase (ST6Gal-I) is only low or not present in normal colonic mucosa cells but high in metastasising colorectal carcinomas. ${ }^{56} \mathrm{Hy}-$ persialylation as the result of enhanced enzyme activity leads to, for example, reduced cell-cell adhesion ${ }^{78}$ and/or increased adhesion of tumour cells to the basal membrane, ${ }^{9}$ and may hamper immune response mechanisms. ${ }^{10}$ Also, mRNA expression and enzyme activity of ST3Gal-I responsible for sialylation of $\mathrm{O}$-glycans is enhanced in colorectal and breast carcinoma specimens. ${ }^{11-13}$ Recently, Recchi and colleagues ${ }^{14}$ showed that high ST3Gal-III and ST6Gal-I expression is associated with poor prognosis of human breast carcinoma.

Fucosyltransferases play an important role in the biosynthesis of tumour associated antigens such as sialyl-Le ${ }^{\mathrm{x}}$ and sialyl-Le ${ }^{\mathrm{a}} .{ }^{15}$ Meanwhile, seven fucosyltransferases have been characterised and sequenced. Transfer of fucose to the $\alpha 1,3-$ position is carried out by fucosyltransferases FT-IV, FT-V, FT-VI, and FT-VII. Fucosyltransferase FT-III (the Lewis enzyme $L e$ ) is active in the formation of $\alpha 1,(3) 4$ linked fucose. Recent studies suggest that FT-III and FT-VI expression in colorectal carcinomas is not significantly altered, but that of FT-IV shows a moderate increase compared with normal mucosa. ${ }^{12}$ Malignant transformation of fibroblast and epithelial cells is accompanied by increased $\beta 1,6-N$-acetylglucosaminyltransferase V (GNT-V) activity, a Golgi $\mathrm{N}$-linked oligosaccharide processing enzyme. ${ }^{16}$ $\beta 1,6$ GlcNAc branching of N-linked oligosaccharides contributes directly to relaxed growth control and reduces substratum adhesion in premalignant epithelial cells. ${ }^{17}$

\section{Materials and methods}

\section{MATERIALS}

Dulbecco's modified Eagle's medium, Iscove's medium, fetal bovine serum, glutamine, guanidinium isothiocyanate/phenol/chloroform, and ethidium bromide were bought from

Abbreviations used in this paper: RT-PCR, reverse transcription-polymerase chain reaction; PHA-L,

Phaseolus vulgaris leucoagglutinating lectin. 
Table 1 Histopathological data of the cases studied

\begin{tabular}{|c|c|c|c|c|c|c|c|c|c|c|}
\hline Sex & Case & Type & Age (y) & $T$ & $N$ & $M$ & $G$ & $L$ & $V$ & $R$ \\
\hline$M$ & 1 & C & 92 & 3 & 0 & 0 & 2 & 0 & 1 & 1 \\
\hline M & 2 & C & 51 & 3 & 0 & 0 & 3 & 0 & 0 & 0 \\
\hline M & 3 & C & 66 & 3 & 0 & 0 & 2 & 0 & 0 & 0 \\
\hline $\mathrm{F}$ & 4 & C & 63 & 3 & 0 & 0 & 2 & 0 & 0 & 0 \\
\hline M & 5 & C & 63 & 3 & 1 & 0 & 3 & 1 & 0 & 0 \\
\hline$M$ & 6 & C & 63 & 3 & 0 & & 1 & 0 & 1 & 0 \\
\hline$M$ & 7 & C & 69 & 2 & 0 & 0 & 2 & 0 & 0 & 0 \\
\hline M & 8 & C & 69 & 4 & 0 & 0 & 2 & 0 & 0 & 0 \\
\hline M & 9 & C & 60 & 3 & 3 & & 3 & 1 & 0 & 0 \\
\hline $\mathrm{F}$ & 10 & C & 24 & & & & & & & \\
\hline $\mathrm{F}$ & 11 & C & 84 & 1 & & 0 & 1 & 0 & 0 & 0 \\
\hline$M$ & 12 & C & 72 & 3 & 2 & 1 & 3 & 1 & 1 & \\
\hline$M$ & 13 & C & 66 & 2 & 0 & 0 & 2 & 0 & 0 & 0 \\
\hline $\mathrm{M}$ & 14 & C & 71 & 4 & 0 & 1 & 1 & 0 & 0 & 2 \\
\hline F & 15 & C & 78 & 2 & 0 & 0 & 2 & 0 & 0 & 0 \\
\hline F & 16 & C & 61 & 3 & 0 & 0 & 1 & 0 & & \\
\hline F & 17 & C & 77 & 3 & 2 & 1 & 2 & 1 & 0 & 2 \\
\hline F & 17 & $\mathrm{LM}$ & 77 & & & 1 & 2 & 0 & 1 & \\
\hline F & 18 & C & 81 & 4 & 0 & 1 & 2 & 2 & & \\
\hline $\mathrm{F}$ & 19 & C & 80 & 3 & 1 & 1 & 2 & 1 & 0 & 0 \\
\hline $\mathrm{M}$ & 20 & C & 69 & 4 & 3 & 1 & 3 & 0 & 0 & 2 \\
\hline$M$ & 20 & $\mathrm{LM}$ & 69 & 4 & 3 & 1 & 3 & 0 & 0 & 2 \\
\hline$M$ & 21 & $\mathrm{C}$ & 70 & 3 & 0 & 1 & 2 & 0 & 0 & 0 \\
\hline M & 21 & LM & 70 & & & 1 & 2 & 0 & 1 & \\
\hline F & 22 & C & 81 & 3 & 3 & 1 & 2 & 1 & 0 & \\
\hline F & 22 & LM & 81 & & & 1 & 2 & 0 & 0 & \\
\hline $\mathrm{F}$ & 23 & C & 49 & 3 & 3 & 0 & 2 & 0 & 0 & 0 \\
\hline $\mathrm{F}$ & 23 & LM & 49 & & & 1 & 2 & 0 & 1 & \\
\hline M & 24 & C & 44 & 3 & 1 & 1 & 2 & 0 & 0 & 0 \\
\hline M & 24 & LM & 44 & & & 1 & 2 & 0 & 1 & \\
\hline F & 25 & LM & 66 & & & 1 & & 0 & 0 & \\
\hline $\mathrm{F}$ & 26 & $\mathrm{LM}$ & 69 & & & 1 & 2 & 0 & 0 & \\
\hline$M$ & 27 & LM & 78 & & & 1 & 2 & 0 & 0 & \\
\hline F & 28 & $\mathrm{LM}$ & 69 & & & 1 & 2 & 0 & 0 & 0 \\
\hline M & 29 & LM & 69 & & & 1 & 2 & 0 & 0 & \\
\hline $\mathrm{F}$ & 30 & $\mathrm{LM}$ & 70 & & & 1 & 2 & 0 & 0 & \\
\hline $\mathrm{F}$ & 31 & $\mathrm{LM}$ & 53 & & & 1 & 2 & 0 & 1 & \\
\hline$M$ & 32 & LM & 70 & & & 1 & 2 & 0 & 0 & 0 \\
\hline $\mathrm{F}$ & 33 & LM & 76 & & & 1 & 2 & 0 & 0 & \\
\hline$M$ & 34 & LM & 61 & & & 1 & 2 & 0 & 1 & 0 \\
\hline $\mathrm{F}$ & 35 & $\mathrm{LM}$ & 73 & & & 1 & 2 & 0 & 0 & \\
\hline
\end{tabular}

Carcinomas were classified and characterised according to the WHO/UICC system.

Type, type of tissue; C, colorectal carcinoma; LM, liver metastasis; T, invasiveness; N, metastasis to regional lymph nodes; $M$, formation of distant metastases; $G$, grading; $L$, lymphatic infiltration; $\mathrm{V}$, venous infiltration. All data were recorded prospectively.

Gibco (Life Technologies, Eggenstein, Germany); Hanks balanced salt solution and phosphate buffered saline were from Biochrom (Berlin, Germany). Cytidine-5'-monophospho- $N$-acetylneuraminic acid, RNase-free DNase, and random hexamers were obtained from Boehringer-Mannheim (Mannheim, Germany). Agarose was from Roth (Karlsruhe, Germany), N-acetyl-lactosamine from CHESS (Mannheim, Germany), cytidine-5'-monophospho- $N-\left[{ }^{3} \mathrm{H}\right]$ acetylneuraminic acid from NENDuPont (Frankfurt, Germany), NH2Lichrosorb column and acetonitrile from Merck (Darmstadt, Germany), and Ultima Gold from Packard (Frankfurt, Germany). Oligonucleotides were synthesised using an Applied Biosystems 380B automated DNA synthesiser and used after high performance liquid chromatography purification (BioTez, Berlin, Germany). All other reagents were obtained from Sigma (München, Germany).

CELL CULTURE

All cell lines were of human origin: colon adenocarcinoma cell lines HT29 (ATCC: HTB-38), HCT-116 (ATCC: CCL-247), and SW480 (ATCC: CCL-228), gastric adenocarcinoma KATO-III (ATCC: HTB-103), and hepatoma line HepG2 (ATCC: HB-8065). The adenocarcinoma lines HT29 and SW480 and also HepG2 were grown in Dulbecco's modified Eagle's medium supplemented with
$10 \%$ fetal bovine serum and $2 \mathrm{mM}$ glutamine. KATO-III and HCT-116 were grown in Iscove's medium supplemented with $10 \%$ fetal bovine serum and $2 \mathrm{mM}$ glutamine. Subconfluent adherent cells were harvested by using a mixture of trypsin (0.05\%) and EDTA $(0.02 \%)$, rescued with their own medium and washed with phosphate buffered saline.

TISSUE

Surgical specimens of patients suffering from colorectal carcinomas were classified and characterised according to the WHO/UICC guidelines (table 1). All data including sex, age, stage of disease, and pathological factors were prospectively recorded. For comparison, tumour tissue, normal mucosa, and, if available, adenoma tissue of the same patient were analysed. Also liver metastases of colorectal carcinomas were compared with normal liver tissue from the same patient. Non-malignant mucosa was scraped off and carcinoma tissue was excised carefully from tumour specimens. Tissue was snap frozen in liquid nitrogen until RNA extraction. In total, 22 samples of colorectal carcinomas and their paired counterparts of normal mucosa, 12 cases of colorectal adenoma, and 17 cases of liver metastasis were studied.

RADIOMETRIC SIALYLTRANSFERASE ASSAY

Cells were washed with ice cold phosphate buffered saline, $\mathrm{pH} 7.3$, at $4^{\circ} \mathrm{C}$. Then cells were pelleted and incubated on a rocking plate for 30 minutes at $4^{\circ} \mathrm{C}$ in $500 \mu 10.25 \mathrm{M}$ sodium cacodylate buffer, $\mathrm{pH}$ 6.5, containing $0.4 \%$ Triton X-100. Supernatants were centrifuged at $32000 \mathrm{~g}$ at $4^{\circ} \mathrm{C}$ for 20 minutes. Protein content in diluted supernatants was determined by the Bio-Rad (München, Germany) protein assay using bovine serum albumin as standard. Standard sialyltransferase assay $(100 \mu \mathrm{l})$ was performed with $50 \mu \mathrm{g}$ protein extract and 1.25 mg $N$-acetyl-lactosamine in $50 \mathrm{mM}$ sodium cacodylate, $\mathrm{pH}$ 6.4, containing $375 \mu \mathrm{g}$ bovine serum albumin, $0.25 \mathrm{mM}$ CDP-choline, 0.25 $\mathrm{mM} \mathrm{MnCl} 2,0.1 \%$ Triton X-100, and $0.5 \mathrm{mM}$ phenylmethanesulfonyl fluoride. Transfer was initiated by the addition of $10 \mathrm{nmol}$ cytidine 5'-monophospho- $N$-acetylneuraminic acid, containing cytidine 5'-monophospho- $N$ $\left[{ }^{3} \mathrm{H}\right]$ acetylneuraminic acid with a radioactivity of $3700 \mathrm{~Bq}(70000 \mathrm{cpm})$. After incubation for up to 300 minutes at $37^{\circ} \mathrm{C}$, the sample was heated for five minutes at $95^{\circ} \mathrm{C}$, centrifuged $(32000 \mathrm{~g})$, and filtered. Separation of 6'- and 3'-sialyl- $N$-acetyl-lactosamine isomers on a $\mathrm{NH}_{2}$-Lichrosorb column was performed as described previously. ${ }^{11}$ Briefly, the chromatograph was run isocratically with 83:17 (v/v) acetonitrile/15 mM KH $\mathrm{KH}_{4}$ for 40 minutes, then the ratio of the mixture was changed to $78: 22$. Fractions of volume $3 \mathrm{ml}$ were collected, and radioactivity counted by liquid scintillation spectrometry in Ultima Gold. One unit of activity is defined as the amount of enzyme catalysing the formation of $1 \mu \mathrm{mol}$ product/ min. 
Table 2 Glycosyltransferase primer sequences

\begin{tabular}{|c|c|c|c|}
\hline Glycosyltransferase & Primer sequence & $\begin{array}{l}\text { Amplicon } \\
\text { length }(b p)\end{array}$ & Reference \\
\hline $\begin{array}{l}\text { FT-I forward } \\
\text { FT-I reverse }\end{array}$ & $\begin{array}{l}\text { TAT TCC GCA TCA CCC TGC } \\
\text { CTG TTC CCG GAG ATG GTG }\end{array}$ & 173 & 38 \\
\hline $\begin{array}{l}\text { FT-III/V forward } \\
\text { FT-III/V reverse }\end{array}$ & $\begin{array}{l}\text { CTG CTG GTG GCT GTG TGT TTC TTC TCC TAC } \\
\text { CAG CCA GCC GTA GGG CGT GAA GAT GTC GGA }\end{array}$ & $447 / 486$ & 49 \\
\hline $\begin{array}{l}\text { FT-IV forward } \\
\text { FT-IV reverse }\end{array}$ & $\begin{array}{l}\text { GGT GCC CGA AAT TGG GCT CCT GCA CAC } \\
\text { CCA GAA GGA GGT GAT GTG GAC AGC GTA }\end{array}$ & 319 & 49 \\
\hline $\begin{array}{l}\text { FT-VI forward } \\
\text { FT-VI reverse }\end{array}$ & $\begin{array}{l}\text { CTC AAG ACG ATC CCA CTG TGT AC } \\
\text { CAG CCA GCC GTA GGG CGT GAA GAT GTC GGA }\end{array}$ & 404 & 49 \\
\hline $\begin{array}{l}\text { FT-VII forward } \\
\text { FT-VII reverse }\end{array}$ & $\begin{array}{l}\text { CTC GGA CAT CTT TGT GCC CTA TG } \\
\text { CGC CAG AAT TTC TCC GTA ATG TAG }\end{array}$ & 288 & 45 \\
\hline $\begin{array}{l}\text { ST3Gal-I forward } \\
\text { ST3Gal-I reverse }\end{array}$ & $\begin{array}{l}\text { ATG AGG TGG ACT TGT ACG GC } \\
\text { AAC GGC TCC AGC AAG ATG }\end{array}$ & 253 & 50 \\
\hline $\begin{array}{l}\text { ST3Gal-III forward } \\
\text { ST3Gal-III reverse }\end{array}$ & $\begin{array}{l}\text { AAC AAG TCT CTG GGG TCA CG } \\
\text { TGA GGA TTC GAA TCT CAG GG }\end{array}$ & 307 & 51 \\
\hline $\begin{array}{l}\text { ST3Gal-IV forward } \\
\text { ST3Gal-IV reverse }\end{array}$ & $\begin{array}{l}\text { CTT CTT CAT GGA GAT TGC AGC } \\
\text { CTA CAG CTC TTG CCC AGG TC }\end{array}$ & 320 & 52 \\
\hline $\begin{array}{l}\text { ST6Gal-I forward } \\
\text { ST6Gal-I reverse }\end{array}$ & $\begin{array}{l}\text { AAA AAC CTT ATC CCT AGG CTG C } \\
\text { TGG TAG TTT TTG TGC CCA CA }\end{array}$ & 379 & 53 \\
\hline $\begin{array}{l}\beta 1,4 \text { GalT forward } \\
\beta 1,4 \text { GalT reverse }\end{array}$ & $\begin{array}{l}\text { TCT ATG TTA TCA ACC AGG CGG } \\
\text { GAT CAT GCG ACA CCT CCC }\end{array}$ & 392 & 54 \\
\hline $\begin{array}{l}\text { GNT-V forward } \\
\text { GNT-V reverse }\end{array}$ & $\begin{array}{l}\text { GTG GAT AGC TTC TGG AAG AA } \\
\text { CAG TCT TTG CAG AGA GCC }\end{array}$ & 856 & 55 \\
\hline $\begin{array}{l}\beta \text {-actin forward } \\
\beta \text {-actin reverse }\end{array}$ & $\begin{array}{l}\text { GGC ATC GTG ATG GAC TCC G } \\
\text { GCT GGA AGG TGG ACA GCG A }\end{array}$ & 622 & 56 \\
\hline
\end{tabular}

Primers for FT-III/V, FT-IV and FT-VI were those published by Yago et al. ${ }^{49}$ All other primers were designed with the HUSAR software according to published glycosyltransferase sequences (references listed in the last column). Amplicons obtained were sequenced and compared with published data.

RT-PCR FOR GLYCOSYLTRANSFERASES

To verify that the sample consists of carcinoma tissue, cryostat sections $(5 \mu \mathrm{m})$ were first examined by a pathologist. Tissue pieces containing necrotic areas, fatty tissue, or a high amount of normal epithelium or stromal tissue were discarded. Carcinoma tissue from adjacent sections or cell pellets were powdered in liquid $\mathrm{N}_{2}$ using a tissue homogeniser (Braun, Melsungen, Germany). RNA was extracted using guanidinium isothiocyanate/phenol/ chloroform $^{19}$ and treated with RNase-free DNase. RNA yield and quality were determined spectrophotometrically using a microplate reader (Tecan, Crailsheim, Germany). Then $5 \mu \mathrm{g}$ of total cellular RNA was reverse transcribed by Moloney murine leukaemia virus reverse transcriptase (ProMega, Mannheim, Germany) with random hexamers. Glycosyltransferase sequences were simultaneously amplified using specific primers (table 2). $\beta$-Actin was co-amplified within the same tube (reaction mixtures as below, with $0.4 \mu \mathrm{l} \beta$-actin

Table 3 Sialyltransferase ST6Gal-I mRNA expression and enzyme activity in human cell lines

\begin{tabular}{lll}
\hline Cell culture & $\begin{array}{l}m R N A \text { expression } \\
(\% \text { actin) }\end{array}$ & $\begin{array}{l}\text { Enzyme activity } \\
(\mu \text { U/mg protein })\end{array}$ \\
\hline HT-29 & $102(23)$ & $62(5.3)$ \\
SW-480 & $176(41)$ & $73(8.1)$ \\
HCT-116 & $51(17)$ & $50(3.5)$ \\
KATO-III & $77(23)$ & $27(2.5)$ \\
HepG2 & $320(76)$ & $180(14.8)$ \\
\hline
\end{tabular}

Values are mean (SD).

Enzyme activity is given in $\mu \mathrm{U} / \mathrm{mg}$ protein content of the cell extract; mRNA-expression as the mean percentage of fluorescence of the sample $v$ fluorescence of $\beta$-actin control. primer and $0.4 \mu \mathrm{l} \mathrm{MgCl}_{2}$ ). For all sample sequences, cycling conditions were one minute at $94^{\circ} \mathrm{C}$, one minute at $59^{\circ} \mathrm{C}$, two minutes at $72^{\circ} \mathrm{C}$. The PCR mixture contained $1.5 \mu \mathrm{l} \mathrm{PCR}$ buffer $(100 \mathrm{mM}$ Tris/HCl, $\mathrm{pH} 8.3,500 \mathrm{mM}$ $\mathrm{KCl}), 1-3 \mathrm{mM} \mathrm{MgCl}_{2}, 5 \mu \mathrm{l}$ sample cDNA, 1.5 $\mu 12 \mathrm{mM}$ dNTPs (Pharmacia, Freiburg, Germany ), $0.2 \mu 1$ AmpliTaq polymerase (Perkin-Elmer), $0.2 \mu 1 \beta$-actin primer (original concentration $0.25 \mu \mathrm{M}$ ), glycosyltransferase specific primer, and water in a final volume of $15 \mu \mathrm{l}$. The volume of glycosyltransferase specific primers (original concentration 50 $\mu \mathrm{M}$ ) was $1 \mu \mathrm{l}$ in reactions to detect GNT-V, 0.8 $\mu \mathrm{l}$ in reactions to detect fucosyltransferases FT-I, FT-VI, FT-VII, and sialyltransferases ST3Gal-I, ST3Gal-IV, and ST6Gal-I, $0.7 \mu \mathrm{l}$ in reactions to detect sialyltransferase ST3GalIII, $0.5 \mu \mathrm{l}$ in reactions to detect $\beta 1,4 \mathrm{Gal}-\mathrm{T}$ and FT-IV, and $0.4 \mu \mathrm{l}$ in reactions to detect fucosyltransferase FT-III/V. The volume of $\mathrm{MgCl}_{2}$ (original concentration $25 \mathrm{mM}$ ) was $1 \mu \mathrm{l}$ in reactions to detect fucosyltransferase FT-VII and sialyltransferases ST3Gal-I and ST6Gal-I, $0.9 \mu \mathrm{l}$ in reactions to detect GNT-V, $0.8 \mu \mathrm{l}$ in reactions to detect $\beta 1,4 \mathrm{Gal}-\mathrm{T}, \quad 0.7 \mu \mathrm{l}$ in reactions to detect fucosyltransferases FT-I, FT-III/V, FT-IV and sialyltransferase ST3GalIII, $0.6 \mu \mathrm{l}$ in reactions to detect sialyltransferase ST3Gal-IV, and $0.5 \mu \mathrm{l}$ in reactions to detect fucosyltransferase FT-VI. Reaction products obtained after $26-28$ cycles were electrophoresed in $3 \%$ agarose containing ethidium bromide. All amplicons obtained were sequenced and compared with published data (table 1). Fluorescence measurements were 
FT-I FTIII FTIV FTVI FTVII STI STIII STIV ST6 Gal-T GNT

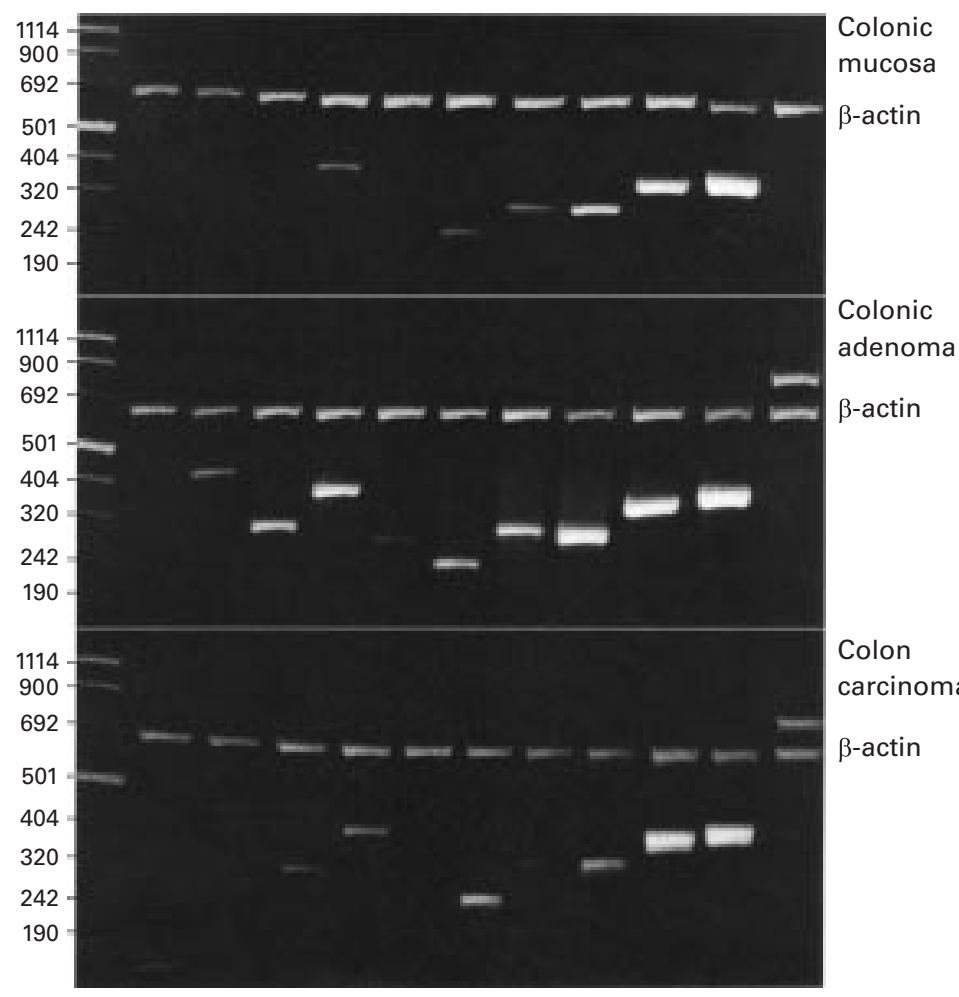

Figure 1 Glycosyltransferase expression in human colorectal tissue from case 3. Fluorescence of electrophoretically resolved, ethidium bromide stained polymerase chain reaction (PCR) products of $\beta$-actin and glycosyltransferase target sequences from colon mucosa, colon adenoma tissue, and colon carcinoma tissue is shown. Glycosyltransferases were amplified as described in Materials and methods. The upper band shows the reaction product of $\beta$-actin amplification. All amplicons were sequenced and compared with published sequences. First lane, molecular mass markers (bp). FT-I, H blood group a1,2-fucosyltransferase I; FTIII-VII, fucosyltransferases III-VII; STI-IV, sialyltransferases ST3Gal-I-IV; ST6, sialyltransferase ST6Gal-I; Gal-T, $\beta 1,4$-galactosyltransferase; GNT, $\beta 1,6-N$-acetylglucosaminyltransferase $V$.

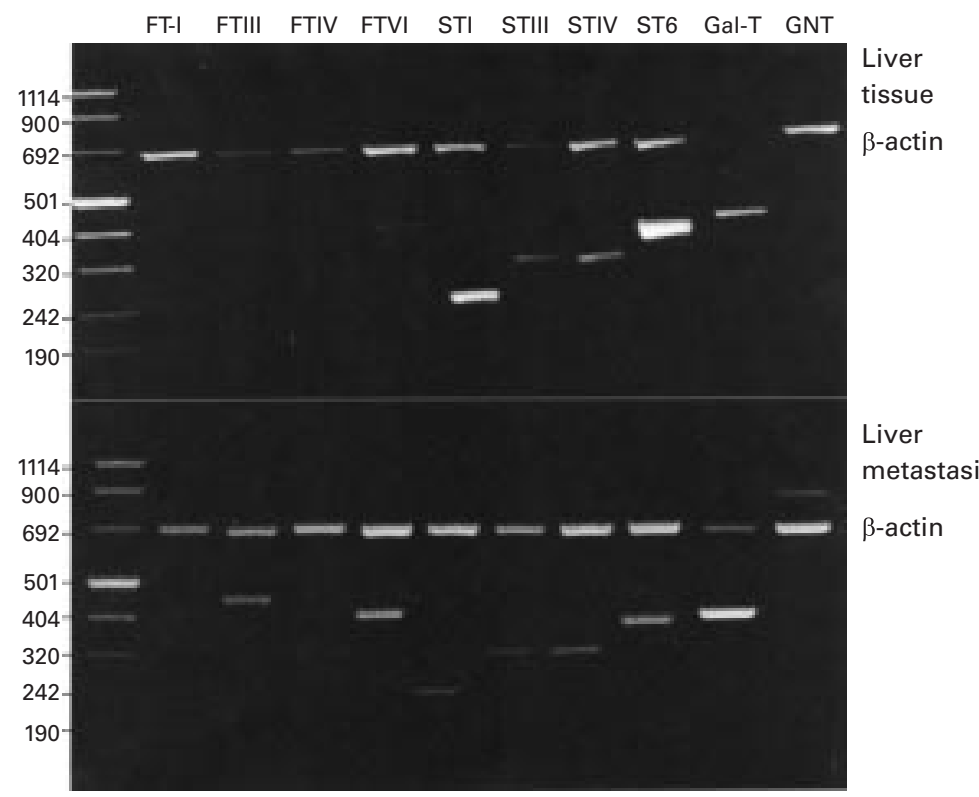

Figure 2 Glycosyltransferase expression in liver and liver metastases of a human colorectal carcinoma from case 35. Fluorescence of electrophoretically resolved, ethidium bromide stained polymerase chain reaction (PCR) products of $\beta$-actin and glycosyltransferase target sequences from normal liver tissue and liver metastases is shown. Glycosyltransferases were amplified as described in Materials and methods. The upper band shows the reaction product of $\beta$-actin amplification. All amplicons were sequenced and compared with published sequences. First lane, molecular mass markers $(b p)$. FT-I, H blood group a1,2-fucosyltransferase I; FTIII-VII, fucosyltransferases III-VII; STI-IV, sialyltransferases ST3Gal-I-IV; ST6, sialyltransferase ST6Gal-I; Gal-T, $\beta 1$,4-galactosyltransferase; GNT, $\beta 1,6-N$-acetylglucosaminyltransferase $V$. made using a Fluor-Imager SI (Molecular Dynamics, Krefeld, Germany). For semiquantitative analysis of the RT-PCR data, fluorescence of each sample was compared with the fluorescence of $\beta$-actin, co-amplified within the same tube. The density of each glycosyltransferase band was compared with the appropriate $\beta$-actin band by calculating the ratio (fluorescence units of glycosyltransferase band/ fluorescence units of $\beta$-actin) $\times 100$. The detection limit was $1 \mathrm{ng}$ double-stranded DNA. The linear portion of the assay ranges up to $25 \mathrm{ng}$. Glycosyltransferase mRNA expression of each sample was determined in at least two independent experiments. Using $\beta$-actin as an internal standard, the deviation between duplicate measurements was on average $27 \%$. The ratio between $\beta$-actin and sample fluorescence was cycle independent between cycle 24 and 28. The Wilcoxon signed rank test was used for statistical analysis of the difference between expression of a given glycosyltransferase in carcinoma and normal tissue of the same patient (matched pairs).

\section{Results}

mRNA EXPRESSION AND ENZYME ACTIVITY OF SIALYLTRANSFERASE ST6Gal-I IN HUMAN CELL LINES

ST6Gal-I mRNA expression in HT-29, SW480, HCT-116, KATO-III, and HepG2 cells was examined by RT-PCR with $\beta$-actin coamplification. The standard deviation between duplicate measurements was $27 \%$. Provided that amplification of both $\beta$-actin and the sample occurs in a linear manner, by coamplification of $\beta$-actin, a semiquantitative analysis of mRNA expression is feasible. For comparison, ST6Gal-I activity in the same samples was determined by the radiometric sialyltransferase assay. ST6Gal-I mRNA expression in human colorectal and gastric carcinoma cell lines correlated well (correlation coefficient $r^{2}=0.9095$ ) with enzyme activity (table 3).

GLYCOSYLTRANSFERASE EXPRESSION IN HUMAN COLORECTAL MUCOSA SPECIMENS, ADENOMAS, AND CARCINOMAS

Enzyme expression was determined by RTPCR simultaneously for all glycosyltransferases under study (table 2). Figure 1 shows RT-PCR of sample no 3 (table 1) as an example. All carcinomas examined (22/22) showed increased GNT-V expression compared with normal mucosa from the same patient $(p<0.001)$. Also, nine of 12 adenomas displayed higher GNT-V expression $(p=0.039)$ than the corresponding mucosa. Expression of FT-IV was enhanced in adenomas $(\mathrm{p}=0.039)$ and colorectal carcinomas $(p<0.001)$; expression of fucosyltransferase FT-I was enhanced $(p<0.001)$ in colorectal carcinomas; expression of FT-V and FT-VII was negligible or undetectable. Among the sialyltransferases, ST3Gal-III expression was enhanced $(p=0.001)$ in adenomas; ST3Gal-I $(\mathrm{p}=0.001)$ and ST6Gal-I $(\mathrm{p}=$ 0.004 ) expression was enhanced in colorectal carcinoma specimens. One case of familial 
Table 4 Glycosyltransferase expression in human colorectal tissue: correlation of glycosyltransferase expression with occurrence of distant metastases

\begin{tabular}{llllll}
\hline$M$ & $N$ & FT-III & FT-IV & FT-VI & GalT \\
\hline 0 & 11 & $150(81)$ & $165(62)$ & $124(89)$ & $368(160)$ \\
1 & 9 & $73(62)$ & $130(50)$ & $58(39)$ & $297(64)$
\end{tabular}

Fucosyltransferase FT-III, FT-IV, FT-VI, and $\beta 1,4$ galactosyltransferase (GalT) mRNA expression in colorectal carcinomas with regard to the presence of distant metastases $(\mathrm{M})$. Values are mean (SD) percentage of sample fluorescence $v$ fluorescence of $\beta$-actin control. $\mathrm{N}$, number of cases.

Table 5 Glycosyltransferase expression in human colorectal tissue: correlation of glycosyltransferase expression with invasiveness

\begin{tabular}{llllll}
\hline$T$ & $N$ & FT-III & FT-IV & FT-VI & GalT \\
\hline 1 or 2 & 4 & $164(106)$ & $147(55)$ & $95(87)$ & $330(51)$ \\
3 & 14 & $107(70)$ & $141(68)$ & $96(79)$ & $345(150)$ \\
4 & 4 & $88(62)$ & $135(57)$ & $79(47)$ & $310(63)$ \\
\hline
\end{tabular}

Fucosyltransferase FT-III, FT-IV, FT-VI, and $\beta 1,4$ galactosyltransferase (GalT) mRNA expression in colorectal carcinomas with regard to invasiveness $(T)$. Values are mean (SD) percentage of sample fluorescence $v$ fluorescence of $\beta$-actin control. $\mathrm{N}$, number of cases.

adenomatous polyposis (case 10) showed high GNT-V expression already in "normal" mucosa and decreased FT-III expression in adenoma tissue.

GLYCOSYLTRANSFERASE EXPRESSION IN HUMAN LIVER SPECIMENS AND LIVER METASTASES

Figure 2 shows RT-PCR of sample no 35 (table 1) as an example. Normal liver specimens showed a high expression of all kinds of sialyltransferases, particularly ST6Gal-I. On the other hand, GNT-V expression was enhanced in liver metastases (14/14) compared with normal liver tissue $(\mathrm{p}<0.001)$. FT-I and FT-VI expression were also enhanced in liver metastases $(p=0.003$ and $p=0.013$ respectively). As opposed to liver metastases, only FT-I expression in three lung metastases was increased (data not shown).

CORRELATION OF GLYCOSYLTRANSFERASE EXPRESSION WITH HISTOPATHOLOGICAL

PARAMETERS

Enzyme expression of the carcinoma specimens was correlated with histopathological parameters (table 1) such as invasiveness ( $\mathrm{T}$ ), presence of lymph node metastases $(\mathrm{N})$, or distant metastases (M) using the Mann-Whitney and Kruskal-Wallis tests. Statistical calculations showed a highly significant correlation between decreased FT-III or FT-VI expression $(p=0.046$ and $p=0.025$ respectively) and the formation of distant metastases (table 4). A decreased FT-III expression correlated $(\mathrm{p}=$ 0.041 ) with tumour infiltration $\mathrm{T}$ (table 5 ). In less differentiated carcinomas $(\mathrm{G}=2$ or $\mathrm{G}=3)$, increased FT-IV expression $(\mathrm{p}=0.064)$ was noticed.

\section{Discussion}

Glycosyltransferases with altered mRNA expression in carcinoma tissue are prognostic factors and potential targets for therapeutic approaches. ${ }^{20}{ }^{21}$ Our aim was to study mRNA expression of a panel of glycosyltransferases in colorectal mucosa, adenomas, and carcinomas, and in liver metastases thereof. Expression of each enzyme was compared with that of $\beta$-actin co-amplified within the same tube. Standard deviation of such measurements ranged between $22 \%$ in the case of ST 3 Gal-IV and 35\% in the case of FT-VI. Statistical calculations were carried out using the difference in mRNA expression between each carcinoma or adenoma and its corresponding normal mucosa. In parallel studies, enzyme activity was determined by a radiometric sialyltransferase assay for several cell lines. ST6Gal-I mRNA expression correlated well with enzyme activity (table 3). Thus alterations in expression of ST6Gal-I mRNA in colorectal carcinoma lines are reflected in the level of enzyme activity.

Major alterations were found above all in mRNA expression of GNT-V. The GNT-V reaction product, $\beta 1,6$ branches on $\mathrm{N}$-glycans of glycoproteins, is found in various tumour cell lines with high metastatic potential. ${ }^{122}$ Examples of substrates for GNT-V activity are the LAMP-2 glycoprotein and integrin glycoproteins $\alpha 5, \alpha \mathrm{v}$, and $\beta 1 .{ }^{17} \mathrm{~A}$ tumour associated increase in $\beta 1,6$ branched oligosaccharides has been described in several studies using lectin histochemistry with the Phaseolus vulgaris leucoagglutinating lectin (PHA-L). ${ }^{23}{ }^{24}$ For example, Fernandes and colleagues ${ }^{25}$ reported in histological sections of colon that adenomas showed a small but significant increase in PHA-L staining compared with normal colonic epithelium while carcinomas showed greatly increased reactivity. Accordingly, we found that GNT-V mRNA expression was significantly enhanced in all colorectal carcinoma tissues as well as in nine of 12 colorectal adenomas examined (fig 3). Moreover, in liver metastases of colorectal carcinomas, GNT-V expression was almost twice that in normal liver tissue (fig 4). Recently, Seelentag and colleagues ${ }^{26}$ showed that PHA-L staining was highly associated with disease free survival in colorectal carcinomas. However, no significant correlation was detected with histological grade or tumour stage; PHA-L correlated only with the presence of lymph nodes. Thus the prognostic value of the presence of $\beta 1,6$-branches synthesised by GNT-V is not reflected by strong correlations with histopathological parameters. No significant correlations between GNT-V expression and tumour staging were detected, only a somewhat enhanced expression of GNT-V in cases with lymph node metastases. As GNT-V expression was already enhanced in adenomas compared with normal mucosa, examination of GNT-V by RT-PCR seems to be best suited for early detection of colorectal tissue alterations. Interestingly, one case of familial adenomatous polyposis (case 10) showed high GNT-V expression already in "normal" mucosa.

Sialic acids are nine carbon sugars which often terminate the oligosaccharide chains of glycoproteins and glycolipids. ${ }^{27}$ The addition of sialic acids to the carbohydrate chains is catalysed by sialyltransferases, a family of at least 20 enzymes which differ in acceptor specificity and the linkage formed with the subterminal sugar residue. Sialyltransferase ST6Gal-I is responsible for the addition of 


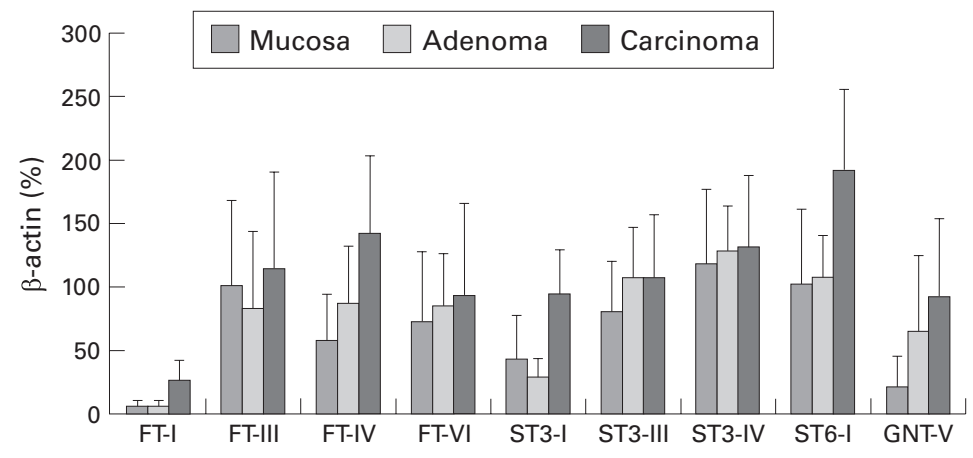

Figure 3 Glycosyltransferase expression in human colorectal tissue. For semiquantitative analysis of the reverse transcription-polymerase chain reaction data, fluorescence of each sample was compared with that of $\beta$-actin co-amplified in the same tube. Standard deviations describe tumour heterogeneity not the accuracy of the assay system. FT-I, H blood group a1,2-fucosyltransferase I; FTIII-VI, fucosyltransferases III-VI; STI-IV, sialyltransferases ST3Gal-I-IV; ST6-I, sialyltransferase ST6Gal-I; GNT-V, $\beta 1,6-N$-acetylglucosaminyltransferase $V$.

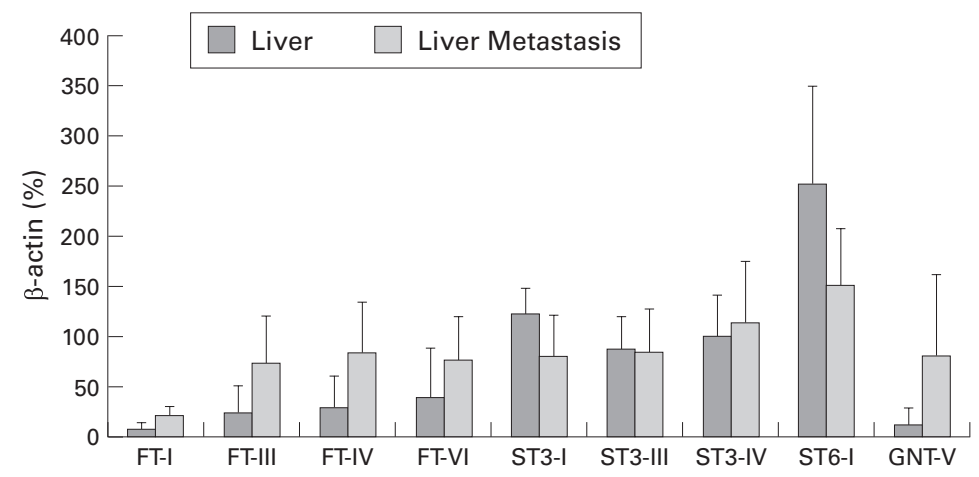

Figure 4 Glycosyltransferase expression in liver metastases of human colorectal carcinomas. For semiquantitative analysis of the reverse transcription-polymerase chain reaction data, fluorescence of each sample was compared with that of $\beta$-actin co-amplified within the same tube. Standard deviations describe tumour heterogeneity not the accuracy of the assay system. FT-I, H blood group a1,2-fucosyltransferase I; FTIII-VI,

fucosyltransferases III-VI; STI-IV, sialyltransferases ST3Gal-I-IV; ST6-I, sialyltransferase ST6Gal-I; GNT-V, $\beta 1,6-N$-acetylglucosaminyltransferase V.

sialic acid in $\alpha 2,6$-linkage to Gal $\beta 1,4 \mathrm{GlcNAc}$ ( $N$-acetyl-lactosamine), a sequence commonly found in N-linked chains of glycoproteins. Transfer of sialic acid in a2,3-linkage to Gal $\beta 1$,(3) 4 GlcNAc on N-linked chains of glycoproteins is carried out by $\alpha 2,3-$ sialyltransferase ST3Gal-III or ST3Gal-IV. The latter is also capable of adding sialic acid to Gal $\beta 1,3$ GalNAc found on O-linked chains of glycoproteins. ST3Gal-I is responsible for $\alpha 2,3$-sialylation of Gal$\beta 1,3$ GalNAc on O-linked chains of glycoproteins and glycolipids, and was proposed to have a decisive role in sialy-Le $\mathrm{Le}^{\mathrm{x}} / \mathrm{Le}^{\mathrm{a}}$ biosynthesis ${ }^{28}$ and sialylation of the Thomsen-Friedenreich antigen. ${ }^{13}$

An examination of the amounts of mRNA for fucosyltransferase and sialyltransferase isoenzymes in human colorectal cancer tissues by northern blotting and RT-PCR was carried out by Ito et al. ${ }^{12}$ They found that the ST3Gal-I message was considerably increased in cancer tissues compared with non-malignant colorectal mucosa, ST3Gal-III expression remained unchanged, whereas that of ST3Gal-IV decreased significantly in cancer tissues. The pronounced increase in the ST3Gal-I message was suggested to be related to enhanced expression of sialylated carbohydrate determinants in colon cancer tissues including sialyl-Le ${ }^{\mathrm{a}}$. Recently, Kudo and colleagues ${ }^{29}$ examined the transcript levels of glycosyltransferase genes by competitive RT-PCR in eight well to moderately differentiated and three poorly differentiated colorectal carcinomas. ST3Gal-II expression was significantly upregulated in all cancerous tissues, ST3Gal-I and ST6Gal-I showed a tendency toward upregulation, and ST3Gal-III showed a tendency toward downregulation. In agreement with these studies, we found a significantly increased expression of ST3Gal-I and ST6Gal-I in colorectal carcinomas (fig 3).

In the case of ST3Gal-IV, Zhang et al, ${ }^{30}$ using serial analysis of gene expression of colorectal tissue obtained from two patients, reported decreased expression in the carcinomas. Also, Ito and colleagues ${ }^{12}$ reported decreased ST3Gal-IV mRNA expression in colorectal carcinomas. However, in the present study downregulation of ST3Gal-IV was detected in only eight of the 22 cases, and Kudo and colleagues ${ }^{29}$ reported a significant upregulation of ST3Gal-IV in poorly differentiated colorectal carcinomas. Thus downregulation of ST3Gal-IV seems to be restricted to certain subpopulations of colorectal carcinomas, which will have to be identified in larger studies.

Fucosyltransferases are classified into two main families based on their acceptor specificity and their primary protein sequence: the $\alpha(1,2)$-fucosyltransferases (FT-I and FT-II) and the $\alpha(1,3)$-fucosyltransferases (FT-III, FT-IV, FT-V, FT-VI, and FT-VII), which are involved in the synthesis of $\mathrm{H}$ and Lewis related antigens respectively. The first one, FT-I, is an $\alpha(1,2)$-fucosyltransferase encoded by the $\mathrm{H}$ gene, ${ }^{31}$ which transfers fucose preferentially to the galactose of terminal type II disaccharide (Gal $\beta 1,4 \mathrm{GlcNAc})$. A second $\alpha(1,2)$-fucosyltransferase, FT-II, encoded by the secretor gene $(\mathrm{Se}){ }^{32}$ transfers fucose preferentially to the galactose of terminal type I disaccharide (Gal $\beta 1,3 \mathrm{GlcNAc}$ ). The $\mathrm{ABH}$ antigens of erythrocytes are the product of $\mathrm{H}$ gene encoded enzyme. People who lack the Se enzyme cannot synthesise the $\mathrm{H}$ type I structure that is a precursor of $\mathrm{A}, \mathrm{B}$, and $\mathrm{Le}^{\mathrm{b}}$ antigens in digestive organ epithelial cells. The glycosylation pattern including $\mathrm{ABH}$ antigens changes during embryonic development, cell maturation, and malignant transformation. ${ }^{33} 34$ In early embryos, the $\mathrm{ABH}$ antigens are expressed on cell surfaces of red blood cells and endothelial and epithelial cells of most organs. Surface expression of the ABH antigens on epithelial cells reaches a maximum at about nine weeks and decreases thereafter. About $50 \%$ of lung carcinomas showed incompatible blood group antigens compared with erythrocytes. Matsumoto and colleagues ${ }^{35}$ reported a correlation between loss of the B-antigen expression and survival $(p<0.05)$ in patients suffering from lung carcinomas. Loss of the antigen was observed more often in metastasising carcinomas. Orntoft and colleagues $^{36}$ detected a loss of glycosyltransferase activity in bladder tumours, which was due to downregulation of $\mathrm{ABH}$ mRNA expression, a mechanism that could be induced by 
increased cell proliferative activity. While the $\mathrm{ABH}, \mathrm{Le}^{\mathrm{y}}$, and $\mathrm{Le}^{\mathrm{b}}$ antigens are expressed in fetal distal colorectal mucosa, they disappear in adult distal colorectal mucosa, but are reexpressed in colorectal carcinoma. ${ }^{37}$ An increase in $\alpha 1,2$-fucosyltransferase activity was found in colorectal carcinoma, ${ }^{37}$ which could be due to an enhanced level of the FT-I transcript. ${ }^{38} \mathrm{Also}$, an increase in tumorigenicity of rat colon cells transfected with FT-I has been reported. ${ }^{39}$ In agreement with these studies, we found significantly increased expression of FT-I in colorectal carcinomas and liver metastases thereof (figs 3 and 4).

FT-III, an $\alpha(1,3 / 1,4)$-fucosyltransferase, corresponds to the Lewis-type fucosyltransferase, thus contributing to the synthesis of $\mathrm{Le}^{\mathrm{x}}$ and $\mathrm{Le}^{\mathrm{y}}, \mathrm{Le}^{\mathrm{a}}, \mathrm{Le}^{\mathrm{b}}$, sialyl-Le ${ }^{\mathrm{x}}$, and sialyl-Le ${ }^{\mathrm{a}}{ }^{40}$ The FT-IV, an $\alpha(1,3)$-fucosyltransferase, corresponds to the myeloid type and contributes to the synthesis of $\mathrm{Le}^{\mathrm{x}}$ and $\mathrm{Le}^{\mathrm{y}} .^{41}{ }^{42}$ FT-V and FT-VI can synthesise $\mathrm{Le}^{\mathrm{x}}, \mathrm{Le}^{\mathrm{y}}$ and sialyl-Le ${ }^{\mathrm{x}}{ }^{43}{ }^{44}$ whereas FT-VII can synthesise only sialyl-Le ${ }^{\mathrm{x}}{ }^{45}$ 46 In agreement with previous results, ${ }^{12}{ }^{29}$ we found that FT-IV expression was greatly increased in colorectal carcinoma specimens. Moreover, FT-IV expression was already increased significantly in adenomas, and an increased FT-IV expression was found in less differentiated carcinomas $(G=2)$. Correlation of glycosyltransferase expression with histopathological parameters (tables 4 and 5) disclosed that FT-III and FT-VI are less abundantly expressed in cases of colorectal carcinoma with distant metastases $(M=1)$. Also, a decreased FT-III expression correlated significantly with tumour invasiveness $(T)$. As FT-III is one of the most abundantly expressed glycosyltransferases in colorectal tissue, ${ }^{29}$ through its loss aberrant structures may be formed by competing enzymes such as FT-IV or sialyltransferases. For instance, Liepkans and colleagues ${ }^{47}$ observed a dramatic decrease in FT-III mRNA in colorectal carcinoma cells after retinoic acid treatment, which corresponded to an increase in sialyl-Le epitope levels. As subterminal fucosylation of lactosyl groups blocks terminal sialylation, less subterminal fucosylation of GlcNAc may permit the prior sialylation of terminal Gal $\beta 1,3$ residues. In another study, Hanski and colleagues ${ }^{48}$ reported that human colon carcinomas that exhibited strong overexpression of sialyl-Le ${ }^{\mathrm{x}}$ showed the same or even lower expression of FT-III mRNA than normal mucosa.

Liver metastases showed lower expression of sialyltransferases but higher expression of fucosyltransferases than normal tissue (figs 3 and 4). For instance, expression of FT-I in liver metastases was significantly higher than in normal liver tissue, but ST6Gal-I expression was reduced. Both traits seem to be original properties of liver-invading colorectal tumour cells. In six cases, biopsy material from normal mucosa, carcinoma, and liver metastases was available. Enzyme expression in liver metastases was similar to that of carcinomas; only GNT-V expression was increased.

In summary, our results show that mRNA expression of several glycosyltransferases is sig- nificantly altered in colorectal adenomas and carcinomas isolated from surgical specimens. A loss of fucosyltransferase FT-III and FT-VI expression may be an initial event for the formation of surface structures that facilitate metastasis. Thus RT-PCR detection of specific glycosyltransferases could be helpful for earlier detection of carcinomas and for assessment of tumour prognosis.

We wish to thank S Grigull and G Franke for excellent technical assistance and the Deutsche Forschungsgemeinschaft (Ke 536/ 2-1) for support.

1 Taniguchi N, Yoshimura M, Miyoshi E, et al. Remodeling of cell surface glycoproteins by $\mathrm{N}$-acetylglucosaminyltransferase III gene transfection: modulation of metastatic potentials and down regulation of hepatitis B virus replication. Glycobiology 1996;6:691-4.

2 Hiraiwa N, Dohi T, Kawakami Kimura N, et al. Suppression of sialyl Lewis X expression and E-selectin-mediated cell adhesion in cultured human lymphoid cells by transfection adhesion in cultured human lymphoid cells by transfection
of antisense cDNA of an alpha13 fucosyltransferase of antisense cDNA of an alpha13 fucosy
(Fuc-T VII). 7 Biol Chem 1996;271:31556-61.

3 Paulson JC, Weinstein J, Schauer A. Tissue-specific expresPaulson JC, Weinstein J, Schauer A. Tissue-specific expres
sion of sialyltransferases. $\mathcal{F}$ Biol Chem 1989;264:10931-4.

4 O'Hanlon TP, Lau KM, Wang XC, et al. Tissue-specific expression of $\beta$-galactoside alpha 2,6-sialyltransferase. $\mathcal{F}$ Biol Chem 1989;264:17389-94.

5 Dall'Olio F, Malagolini N, DiStefano G, et al. Increased CMP-NeuAc:Galß1,4GlcNAc-R $\alpha 2,6$-sialyltransferase activity in human colorectal cancer tissues. Int $\mathcal{F}$ Cancer 1989; 44:434-9.

6 Gessner P, Riedl S, Quentmaier A, et al. Enhanced activity of CMP-NeuAc:Galbeta 1-4GlcNAc:alpha 2,6- sialyltransferase in metastasizing human colorectal tumor tissue
and serum of tumor patients. Cancer Lett 1993;75:143-9.

7 Dall'Olio F, Malagolini N, Serafini Cessi F. Enhanced CMP-NeuAc:Galbeta 1,4GlcNAc-R alpha 2,6 sialyltransferase activity of human colon cancer xenografts in athymic nude mice and of xenograft-derived cell lines. Int 7 Cancer 1992;50:325-30.

8 Bosch J, Brossmer R, Kemmner W, et al. Preparation and characterization of differently aggregated colorectal carcinoma cell subpopulations from surgical specimens. Cancer Detect Prev 1998;22:319-29.

9 Morgenthaler J, Kemmner W, Brossmer R. Sialic acid dependent cell adhesion to collagen IV correlates with in vivo tumorigenicity of the human colon carcinoma sublines HCT116, HCT116a and HCT116b. Biochem Biophys Res Commun 1990;171:860-6.

10 Pilatte Y, Bignon J, Lambre CR. Sialic acids as important molecules in the regulation of the immune system: pathophysiological implications of sialidases in immunity. Glycobiology 1993;3:201-17.

11 Kemmner W, Kruck D, Schlag P. Different sialyltransferase activities in human colorectal carcinoma cells from surgical specimens detected by specific glycoprotein and glycolipid acceptors. Clin Exp Metastasis 1994;12:245-54.

12 Ito H, Hiraiwa N, Sawada Kasugai M, et al. Altered mRNA expression of specific molecular species of fucosyl- and expression of specific molecular species of fucosyl- and
sialyl-transferases in human colorectal cancer tissues. Int $\mathcal{F}$ Sialyl-transferases in hum

13 Whitehouse C, Burchell J, Gschmeissner S, et al. A transfected sialyltransferase that is elevated in breast cancer and localizes to the medial/trans-Golgi apparatus inhibits the development of core-2-based O-glycans. F Cell Biol 1997;137:1229-41.

14 Recchi MA, Hebbar M, Hornez L, et al. Multiplex reverse transcription polymerase chain reaction assessment of sialyltransferase expression in human breast cancer. Cancer Res 1998;58:4066-70.

15 Natsuka S, Lowe JB. Enzymes involved in mammalian oligosaccharide biosynthesis. Curr Opin Struct Biol 1994;4: 683-91

16 Dennis JW. N-linked oligosaccharide processing and tumor cell biology. Semin Cancer Biol 1991;2:411-20.

17 Demetriou M, Nabi IR, Coppolino M, et al. Reduced contact-inhibition and substratum adhesion in epithelial colls expressing GlcNAc-transferase V. F Cell Biol 1995;130: 383-92.

18 Reference withdrawn

19 Chomczynski P, Sacchi N. Single-step method of RNA isolation by acid guanidinium thiocyanate-phenol-chloroform extraction. Anal Biochem 1987;162:156-9.

20 Orntoft TF, Vestergaard EM. Clinical aspects of altered glycosylation of glycoproteins in cancer. Electrophoresis 1999; 20:362-71.

21 Kemmner W, Hohaus K, Schlag PM. Inhibition of Gal beta1, 4GlcNAc alpha2,6 sialyltransferase expression by
antisense-oligodeoxynucleotides. FEBS Lett 1997;409: 347-50.

22 Dennis JW, Laferte S, Waghorne C, et al. $\beta 1-6$ branching of ASN-linked oligosaccharides is directly associated with metastasis. Science 1987;236:582-5.

23 Korczak B, Goss P, Fernandez B, et al. Branching N-linked oligosaccharides in breast cancer. Adv Exp Med Biol 1994; 353:95-104 
$24 \mathrm{Li}$ WP, Zuber C, Heitz PU, et al. Cytochemical staining for beta 1,6 branching of asparagine-linked oligosaccharides in variants of metastatic human colon carcinoma cells. $A m \mathcal{F}$

Pathol 1994;145:470-80.

25 Fernandes B, Sagman U, Auger M, et al. Beta 1-6 branched oligosaccharides as a marker of tumor progression in human breast and colon neoplasia. Cancer Res 1991;51: 718-23.

26 Seelentag WK, Li WP, Schmitz SF, et al. Prognostic value of beta1,6-branched oligosaccharides in human colorecta carcinoma. Cancer Res 1998;58:5559-64.

27 Schauer R. Biosynthesis and function of $\mathrm{N}$ - and O-substituted sialic acids. Glycobiology 1991;1:449-52

28 Kannagi R. Carbohydrate-mediated cell adhesion involved in hematogenous metastasis of cancer. Glycoconj 7 1997;14 577-84.

29 Kudo T, Ikehara Y, Togayachi A, et al. Up-regulation of a set of glycosyltransferase genes in human colorectal cancer.
Lab Invest 1998;78:797-811.

30 Zhang L, Zhou W, Velculescu VE, et al. Gene expression profiles in normal and cancer cells. Science 1997;276:1268prof

31 Larsen RD, Ernst LK, Nair RP, et al. Molecular cloning, sequence, and expression of a human GDP-L-fucose:betaD-galactoside 2-alpha-L-fucosyltransferase cDNA that can form the H blood group antigen. Proc Natl Acad Sci USA 1990;87:6674-8.

32 Kelly RJ, Rouquier S, Giorgi D, et al. Sequence and expression of a candidate for the human Secretor blood group alpha(1,2)fucosyltransferase gene (FUT2). Homozygosity for an enzyme-inactivating nonsense mutation commonly correlates with the non-secretor phenotype. 7 Biol Chen 1995;270:4640-9.

33 Hakomori S. Aberrant glycosylation in tumors and tumorassociated carbohydrate antigens. Adv Cancer Res 1989;52: 257-331.

34 Oriol R, Mollicone R, Coullin P, et al. Genetic regulation of the expression of $\mathrm{ABH}$ and Lewis antigens in tissues. the expression of $\mathrm{ABH}$ and

35 Matsumoto H, Muramatsu H, Shimotakahara T, et al. Correlation of expression of $\mathrm{ABH}$ blood group carbohydrate antigens with metastatic potential in human lung carcinoantigens with metastatic poten
mas. Cancer 1993;72:75-81.

36 Orntoft TF, Meldgaard P, Pedersen B, et al. The blood group $\mathrm{ABO}$ gene transcript is down-regulated in human bladder tumors and growth-stimulated urothelial cell lines. Cancer Res 1996;56:1031-6.

37 Orntoft TF, Greenwell P, Clausen H, et al. Regulation of the oncodevelopmental expression of type 1 chain $\mathrm{ABH}$ and Lewis(b) blood group antigens in human colon by alpha-2L-fucosylation. Gut 1991;32:287-93.

38 Sun J, Thurin J, Cooper HS, et al. Elevated expression of $\mathrm{H}$ type GDP-L-fucose:beta-D-galactoside alpha-2-L-fucosyltransferase is associated with human colon adenocarcinoma progression. Proc Natl Acad Sci USA 1995;92:57248 .

39 Goupille C, Hallouin F, Meflah K, et al. Increase of rat colon carcinoma cells tumorigenicity by alpha $(1-2)$ fucosyltranscarcinoma cells tumorigenicity by alpha(1-2) fucosy
ferase gene transfection. Glycobiology 1997;7:221-9.

40 Kukowska Latallo JF, Larsen RD, Nair RP, et al. A cloned human cDNA determines expression of a mouse stagespecific embryonic antigen and the Lewis blood group alpha $(1,3 / 1,4)$ fucosyltransferase. Genes Dev 1990;4:1288303.

41 Kumar R, Potvin B, Muller WA, et al. Cloning of a human alpha(1,3)-fucosyltransferase gene that encodes ELFT but does not confer ELAM-1 recognition on Chinese hamster ovary cell transfectants. F Biol Chem 1991;266:21777-83.

42 Lowe JB, Kukowska Latallo JF, Nair RP, et al. Molecular cloning of a human fucosyltransferase gene that determines expression of the Lewis $\mathrm{x}$ and VIM-2 epitopes but not ELAM-1-dependent cell adhesion. $\mathcal{F}$ Biol Chem 1991;266: 17467-77.

43 Koszdin KL, Bowen BR. The cloning and expression of a human alpha-1,3 fucosyltransferase capable of forming the E-selectin ligand. Biochem Biophys Res Commun 1992;187: $152-7$.

44 Weston BW, Nair RP, Larsen RD, et al. Isolation of a novel human alpha $(1,3)$ fucosyltransferase gene and molecular comparison to the human Lewis blood group alpha (1, $3 / 1,4)$ fucosyltransferase gene. Syntenic, homologous, nonallelic genes encoding enzymes with distinct acceptor substrate specificities. F Biol Chem 1992;267:4152-60.

45 Natsuka S, Gersten KM, Zenita K, et al. Molecular cloning of a cDNA encoding a novel human leukocyte alpha-1,3fucosyltransferase capable of synthesizing the sialyl Lewis $\mathrm{x}$ determinant. F Biol Chem 1994;269:16789-94.

46 Sasaki K, Kurata K, Funayama K, et al. Expression cloning of a novel alpha 1,3-fucosyltransferase that is involved in biosynthesis of the sialyl Lewis $\mathrm{x}$ carbohydrate determinants in leukocytes. F Biol Chem 1994;269:14730-7.

47 Liepkalns VA, Eboue D, Beringer T, et al. Repression of the Lewis fucosyl transferase by retinoic acid increases apical sialosyl Lewis(a) secretion in colorectal carcinoma cultures. 7 Cell Biochem 1995;58:292-304.

48 Hanski C, Klussmann E, Wang J, et al. Fucosyltransferase III and sialyl-Le(x) expression correlate in cultured colon carcinoma cells but not in colon carcinoma tissue. Glycoconj F 1996;13:727-33.

49 Yago K, Zenita K, Ginya H, et al. Expression of alpha- $(1,3)-$ fucosyltransferases which synthesize sialyl Le(x) and sialyl $\mathrm{Le}(\mathrm{a})$, the carbohydrate ligands for $\mathrm{E}$ - and P-selectins, in human malignant cell lines. Cancer Res 1993;53:5559-65.

50 Kitagawa H, Paulson JC. Cloning of a novel alpha 2,3-sialyltransferase that sialylates glycoprotein and glycoli2,3-sialyltransferase that sialylates glycoprotein and glycoli-
pid carbohydrate groups. F Biol Chem 1994;269:1394-401.

51 Kitagawa H, Paulson JC. Cloning and expression of human Gal beta 1,3(4)GlcNAc alpha 2,3-sialyltransferase. Biochem Biophys Res Commun 1993;194:375-82.

52 Sasaki K, Watanabe E, Kawashima K, et al. Expression cloning of a novel Gal beta (1-3/1-4) GlcNAc alpha 2, 3 -sialyltransferase using lectin resistance selection. F Biol Chem 1993;268:22782-7.

53 Grundmann U, Nehrlich C, Rein T, et al. Complete cDNA sequence encoding human $\beta$-galactoside alpha 2,6- sialyltransferase. Nucleic Acids Res 1994;18:667.

54 Masri KA, Appert HE, Fukuda MN. Identification of the full-length coding sequence for human galactosyltransferase (beta-N-acetylglucosaminide: beta 1,4-galactosyltransferase). Biochem Biophys Res Commun 1988;157:65763.

55 Saito H, Nishikawa A, Gu J, et al. cDNA cloning and chromosomal mapping of human $\mathrm{N}$-acetylglucosaminyltransferase V+. Biochem Biophys Res Commun 1994;198: 318-27.

56 Ponte P, Ng SY, Engel J, et al. Evolutionary conservation in the untranslated regions of actin mRNAs: DNA sequence of a human beta-actin cDNA. Nucleic Acids Res 1998;12: $1687-96$ 